\title{
Article \\ Phase Transformations upon Ageing in Ti15Mo Alloy Subjected to Two Different Deformation Methods
}

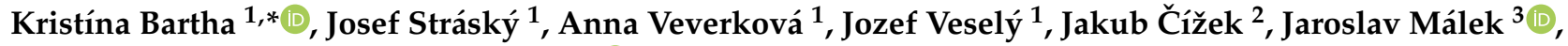 \\ Veronika Polyakova ${ }^{4}$, Irina Semenova ${ }^{4}\left(\mathbb{D}\right.$ and Miloš Janeček ${ }^{1}$ \\ 1 Department of Physics of Materials, Charles University, 12116 Prague, Czech Republic; \\ josef.strasky@gmail.com (J.S.); veverkova@karlov.mff.cuni.cz (A.V.); vesely@gjh.sk (J.V.); \\ janecek@met.mff.cuni.cz (M.J.) \\ 2 Department of Low Temperature Physics, Charles University, 18000 Prague, Czech Republic; \\ jcizek@nbox.troja.mff.cuni.cz \\ 3 Faculty of Mechanical Engineering, Czech Technical University in Prague, 12135 Prague, Czech Republic; \\ jardamalek@seznam.cz \\ 4 Institute of Physics of Advanced Materials, Ufa State Aviation Technical University, Ufa 450008, Russia; \\ vnurik@gmail.com (V.P.); semenova-ip@mail.ru (I.S.) \\ * Correspondence: kristina.bartha@met.mff.cuni.cz; Tel.: +420-95155-1361
}

check for

updates

Citation: Bartha, K.; Stráský, J.; Veverková, A.; Veselý, J.; Č́ížek, J.; Málek, J.; Polyakova, V.; Semenova, I.; Janeček, M. Phase Transformations upon Ageing in Ti15Mo Alloy Subjected to Two Different Deformation Methods. Metals 2021 11, 1230. https://doi.org/10.3390/ met11081230

Academic Editor: Maciej Motyka

Received: 30 June 2021

Accepted: 30 July 2021

Published: 2 August 2021

Publisher's Note: MDPI stays neutral with regard to jurisdictional claims in published maps and institutional affiliations.

Copyright: (c) 2021 by the authors. Licensee MDPI, Basel, Switzerland. This article is an open access article distributed under the terms and conditions of the Creative Commons Attribution (CC BY) license (https:// creativecommons.org/licenses/by/ $4.0 /)$.

\begin{abstract}
Ti15Mo alloy was subjected to two techniques of intensive plastic deformation, namely high pressure torsion and rotary swaging at room temperature. The imposed strain resulted in the formation of an ultrafine-grained structure in both deformed conditions. Detailed inspection of the microstructure revealed the presence of grains with a size of around $100 \mathrm{~nm}$ in both conditions. The microstructure after rotary swaging also contained elongated grains with a length up to $1 \mu \mathrm{m}$. Isothermal ageing at $400{ }^{\circ} \mathrm{C}$ and $500{ }^{\circ} \mathrm{C}$ up to $16 \mathrm{~h}$ was applied to both conditions to investigate the kinetics of precipitation of the $\alpha$ phase and the recovery of lattice defects. Positron annihilation spectroscopy indicated that the recovery of lattice defects in the $\beta$ matrix had already occurred at $400{ }^{\circ} \mathrm{C}$ and, in terms of positron trapping, was partly compensated by the precipitation of incoherent $\alpha$ particles. At $500{ }^{\circ} \mathrm{C}$ the recovery was fully offset by the formation of incoherent $\alpha / \beta$ interfaces. Contrary to common coarse-grained material, in which the $\alpha$ phase precipitates in the form of lamellae, precipitation of small and equiaxed $\alpha$ particles occurred in the deformed condition. A refined two-phase equiaxed microstructure with $\alpha$ particles and $\beta$ grain sizes below $1 \mu \mathrm{m}$ is achievable by simple rotary swaging followed by ageing.
\end{abstract}

Keywords: metastable $\beta$-Ti alloy; severe plastic deformation; rotary swaging; $\alpha$ phase precipitation; defect structure

\section{Introduction}

Thanks to their excellent mechanical properties, titanium alloys have extensive use in the aerospace as well as in the biomedical industry [1,2]. Ti-6Al-4V alloy still belongs to the most used alloy in the biomedical field. However, in recent years, biological safety has become a crucial issue in the development of biomedical metallic materials [3]. In the human body, small amounts of harmful elements, such Al or V can trigger an allergic reaction [4]. Therefore, metastable $\beta$-Ti alloys, which have comparable mechanical properties to Ti-6Al-4V alloy but contain only nontoxic elements, are considered to be appropriate candidates for surgical and orthopaedic implant manufacturing [5]. Current research focuses on the development of biocompatible metastable $\beta$-Ti alloys and the improvement of their mechanical properties.

Methods of severe plastic deformation (SPD) can be applied to enhance the strength of these alloys [6,7]. Materials subjected to SPD methods possess a high density of lattice defects and often exhibit an ultrafine-grained structure (UFG) [8]. 
Another approach to improve the mechanical properties of metastable $\beta$-Ti alloys is to apply a thermal treatment. Precipitation of the $\alpha$ phase results in improving the strength and ductility of these alloys [9-12]. However, volume fraction, size, morphology, and distribution of the $\alpha$ precipitates in the $\beta$ matrix need to be appropriately engineered. The $\alpha$ phase typically nucleates heterogeneously at $\beta$ grain boundaries, phase boundaries, dislocations and inclusions in the matrix $[13,14]$.

The combination of intensive plastic deformation (such as SPD) and subsequent heat treatment leads to the precipitation of small, equiaxed and finely dispersed $\alpha$ precipitates, as reported in our previous studies [15-17] and in other studies [18,19]. Moreover, some authors previously reported improved strength of these deformed and aged metastable $\beta$-Ti alloys $[19,20]$.

In this study a metastable $\beta$-Ti alloy, Ti15Mo (in $w t \%$ ) was investigated. The nondeformed (solution treated) condition contains a $\beta$ matrix and metastable $\omega$ phase as it was reported in our previous study [15-17]. The material after solution treatment was deformed by high pressure torsion (HPT), which is a type of SPD method, and alternatively using cold-rotary swaging (RS). RS is a common and relatively simple deformation method, which produces material with a high density of dislocations (similarly to SPD). Unlike HPT, RS produces significantly larger samples, which can consequently be applied in product manufacturing.

This study aims to investigate the precipitation of $\alpha$ particles in the two deformed conditions, i.e., HPT and RS, and in particular, the effect of different types of lattice defects (dislocations, grain boundaries) on the nucleation of $\alpha$ particles. The potential use of RS instead of HPT as a deformation method is also discussed.

\section{Materials and Methods}

The examined Ti15Mo alloy was supplied by Carpenter Co. (Richmond, VA, USA). A rod with a $10 \mathrm{~mm}$ diameter was solution treated (ST) in an inert Ar atmosphere at a temperature of $810^{\circ} \mathrm{C}$ for $4 \mathrm{~h}$ followed by water quenching. The ST alloy was deformed in two different ways: high pressure torsion and rotary swaging.

Cylindrical specimens cut from the ST rod were used for HPT processing. The deformation was performed at room temperature at Ufa State Aviation Technical University, Russian Federation. First, the cylindrical samples were pressed by 6 GPa to achieve disk-shaped samples with a diameter of $20 \mathrm{~mm}$ and thickness of approximately $1 \mathrm{~mm}$. Subsequently, the specimens were deformed in torsion by rotating one of the anvils. The detailed description of the HPT method can be found in a different study [21]. For this investigation, specimens after $N=1 \mathrm{HPT}$ rotation were prepared. Due to the nature of the deformation, the equivalent deformation is inhomogeneous and, according to the von Mises equation [22], can reach $36(3600 \%)$ at the periphery of the sample.

The ST rod was also used to perform cold-rotary swaging at the company ÚJP Praha, Czech Republic. The final diameter of the rod after RS was $5 \mathrm{~mm}$ which corresponds to a $75 \%$ reduction of the area. Due to the nature of RS, the resulting structure is also inhomogeneous [23]. All measurements were undertaken on the peripheral part of the samples, where the deformation reaches its highest values.

Both materials after HPT and RS (hereafter referred as HPT and RS samples, respectively) were aged at temperatures of $400{ }^{\circ} \mathrm{C}$ and $500{ }^{\circ} \mathrm{C}$ for 1,4 and $16 \mathrm{~h}$. Ageing was performed by immersing the samples into a preheated salt-bath (i.e., with a very high heating rate and without air access) and terminated by water quenching. All samples were mechanically ground and polished by standard methods followed by three-step vibratory polishing.

A scanning electron microscope (SEM) Zeiss Auriga Compact CrossBeam) (Carl Zeiss AG, Jena, Germany) was used for SEM analysis. Standard back-scattered electron (BSE) observations were performed at an accelerating voltage of $10 \mathrm{kV}$.

A transmission electron microscope (TEM) JEOL 2200 FS (Jeol Ltd., Tokyo, Japan) equipped with selected area electron diffraction (SAED) and automated crystallographic 
orientation mapping (ACOM-TEM) was operated at an accelerating voltage of $200 \mathrm{kV}$ and was used for detailed microstructure observation.

The evolution of lattice defects with ageing was determined by positron annihilation spectroscopy (PAS). Positron lifetime measurements were carried out using a highresolution digital spectrometer, described in detail in a previous study [24]. The digital lifetime spectrometer is equipped with two Hamamatsu H3378 photomultipliers (Hamamatsu Photonics K.K., Hamamatsu City, Japan) coupled with $\mathrm{BaF}_{2}$ scintillators. Detector pulses are sampled by two ultrafast Acqiris DC211 8-bit digitizers (Acqiris SA, Plan-lesOuates, Switzerland) at a sampling frequency of $4 \mathrm{GHz}$. The digitized pulses are analyzed off-line by software using a new algorithm for integral constant fraction timing [25]. The time resolution of the spectrometer was $145 \mathrm{ps}$. At least $10^{7}$ annihilation events were accumulated in each lifetime spectrum. A decomposition of the lifetime spectra into exponential components was performed by a maximum likelihood code described in [26].

\section{Results}

The severely deformed microstructure of the Ti15Mo alloy after HPT is shown in the bright field (BF) TEM micrograph (Figure 1a). Figure 1b shows a dark field (DF) image from a $\beta$ phase reflection. The individual grains of the $\beta$ phase are not fully recognizable due to severe fragmentation, but their size is clearly below $200 \mathrm{~nm}$. The corresponding SAED pattern displayed in Figure 1c confirms that HPT material contains both $\beta$ and $\omega$ phases. The distortion of the individual spots in the SAED pattern suggests a severely deformed and fragmented $\beta$ matrix with a strong texture in the direction $[111]_{\beta}$.
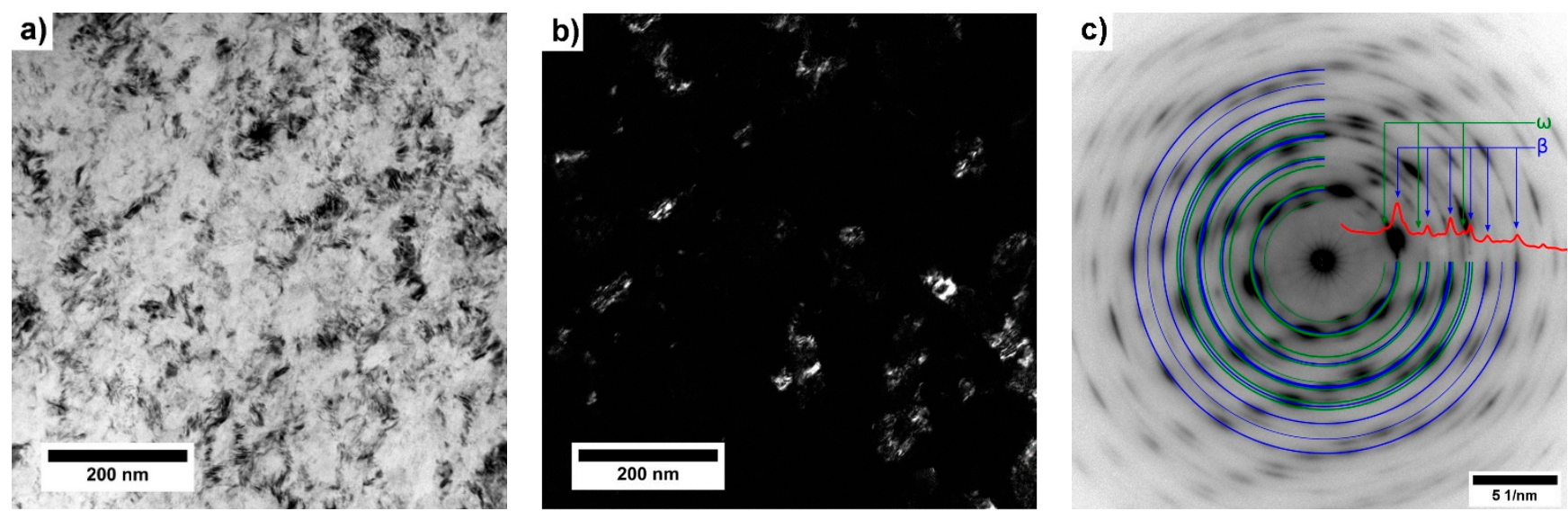

Figure 1. (a) TEM bright field image, (b) TEM dark field image and (c) the corresponding SAED pattern of the material after $N=1$ turn of HPT deformation on the peripheral part of the sample. The dark field image was obtained from an arbitrarily selected part of the diffraction rings shown in Figure 1c.

The BF and DF images of the RS specimens in Figure 2a,b, respectively, indicate a highly deformed microstructure. The microstructure contains fragmented and partly elongated grains with sizes below $500 \mathrm{~nm}$ (note the lower magnification of the images in Figure 2 compared to Figure 1). Figure 2c, showing the corresponding SAED pattern, confirms that the RS material contains $\beta$ and $\omega$ phases. However, the volume fraction of the $\omega$ phase seems to be higher in the HPT sample compared to the RS one. It can be caused by the deformation induced $\omega$ phase after SPD processing, as reported in study [27].

The microstructure of both the HPT and the RS specimens was also investigated using the ACOM-TEM technique. The inverse pole figure (IPF) map in Figure 3a also confirms the nanocrystalline character of the microstructure after HPT straining, with the majority of grains below $100 \mathrm{~nm}$. Due to the character of HPT straining, most of the grains exhibit the typical $\langle 111\rangle$ texture. The IPF map in Figure 3b shows the severely distorted microstructure of the RS specimen, containing elongated grains with a length of up to $1 \mu \mathrm{m}$ and more equiaxed and smaller grains with sizes below $100 \mathrm{~nm}$. The black areas of the image cannot 
be successfully indexed, which suggests a very high dislocation density. Note also that the majority of the grains, namely the larger elongated ones, exhibit preferred crystallographic orientation $\langle 110\rangle$, parallel with the axial direction of the rod.
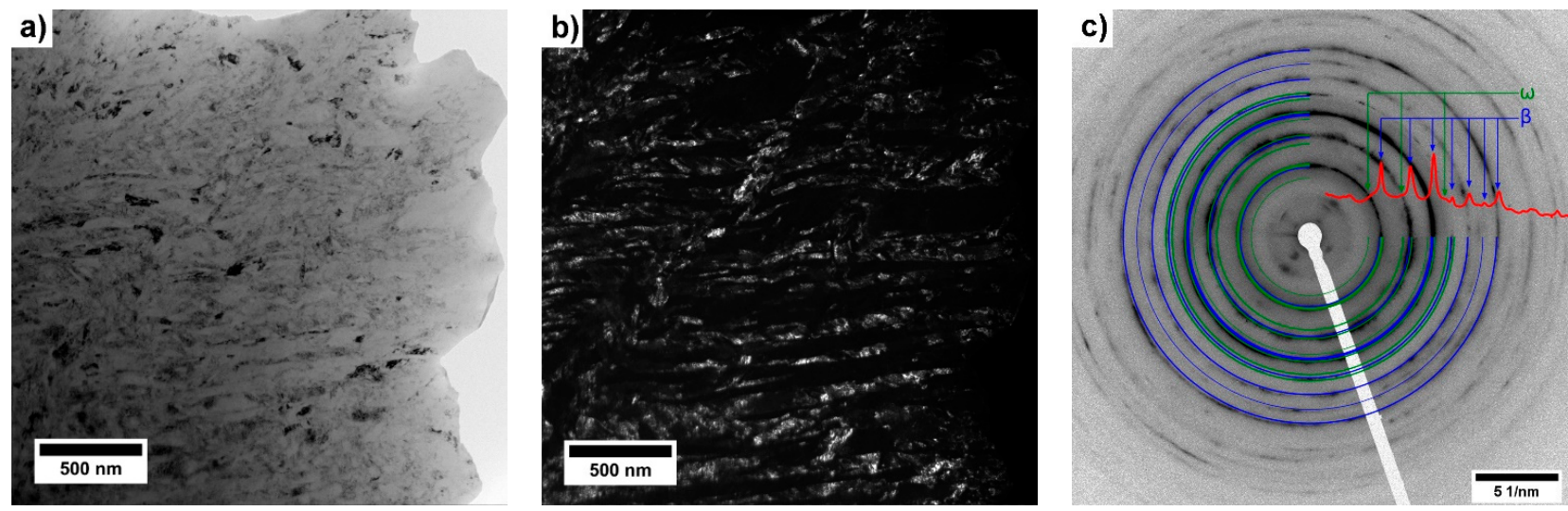

Figure 2. (a) TEM bright field image, (b) TEM dark field image and (c) the corresponding SAED pattern of the RS material. The dark field image was obtained from an arbitrarily selected part of the diffraction rings shown in Figure 2c.
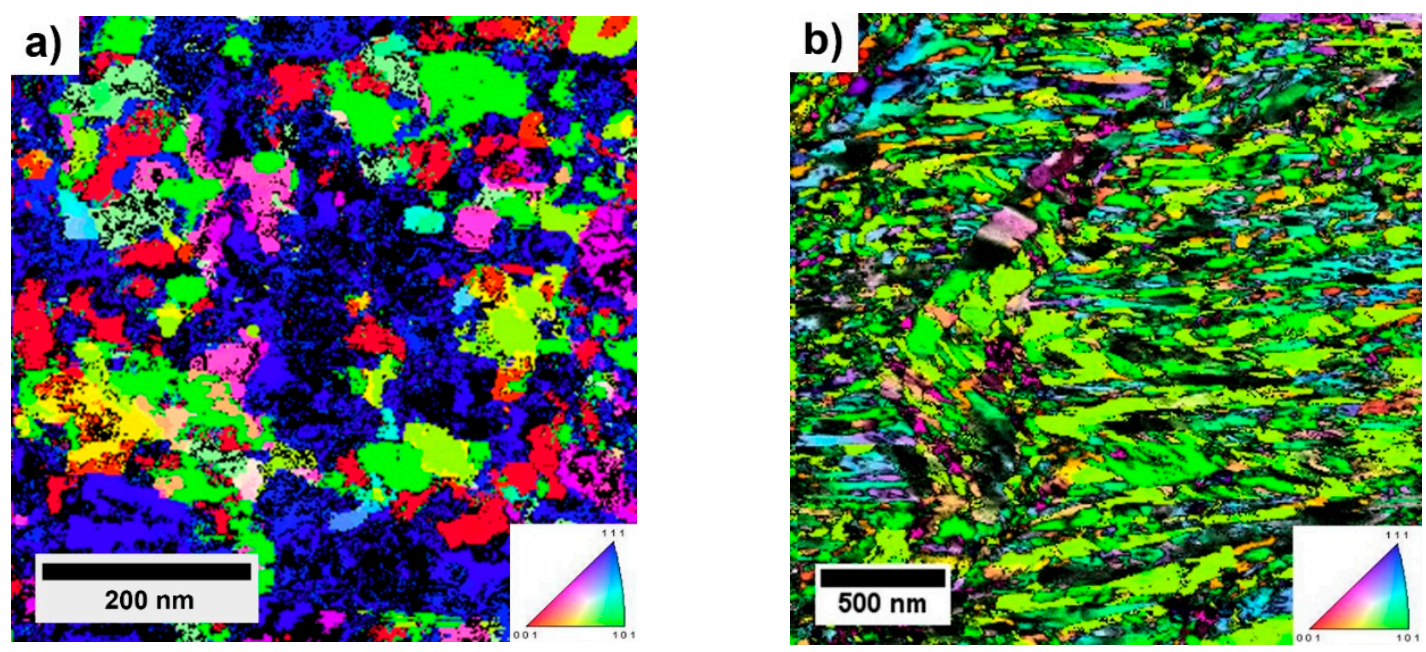

Figure 3. IPF map obtained using ACOM-TEM technique and the corresponding orientation triangle for BCC structure (a) HPT, (b) RS condition.

Figures 4 and 5 show the microstructure of the Ti15Mo alloy after isothermal ageing of the alloy previously deformed by HPT and RS, respectively. The contrast in the images is given by the chemical composition of the material-the so-called Z-contrast. As the $\alpha$ phase contains a lower amount of Mo than the $\beta$ phase, it appears darker. In both materials, the particles of the $\alpha$ phase are small and equiaxed. These polygonal phase particles are observed in all conditions in both Figures 4 and 5. Their size and volume fraction increase with an increasing temperature and time of ageing; however, the precipitation is inhomogeneous even after ageing at $500{ }^{\circ} \mathrm{C} / 16 \mathrm{~h}$. The possible cause of the inhomogeneity is thoroughly discussed in the Discussion section.

Differences in the microstructures of HPT and RS samples can be observed already after ageing at $400{ }^{\circ} \mathrm{C} / 1 \mathrm{~h}$-more $\alpha$ phase particles precipitated in the HPT specimens compared to the RS ones. 

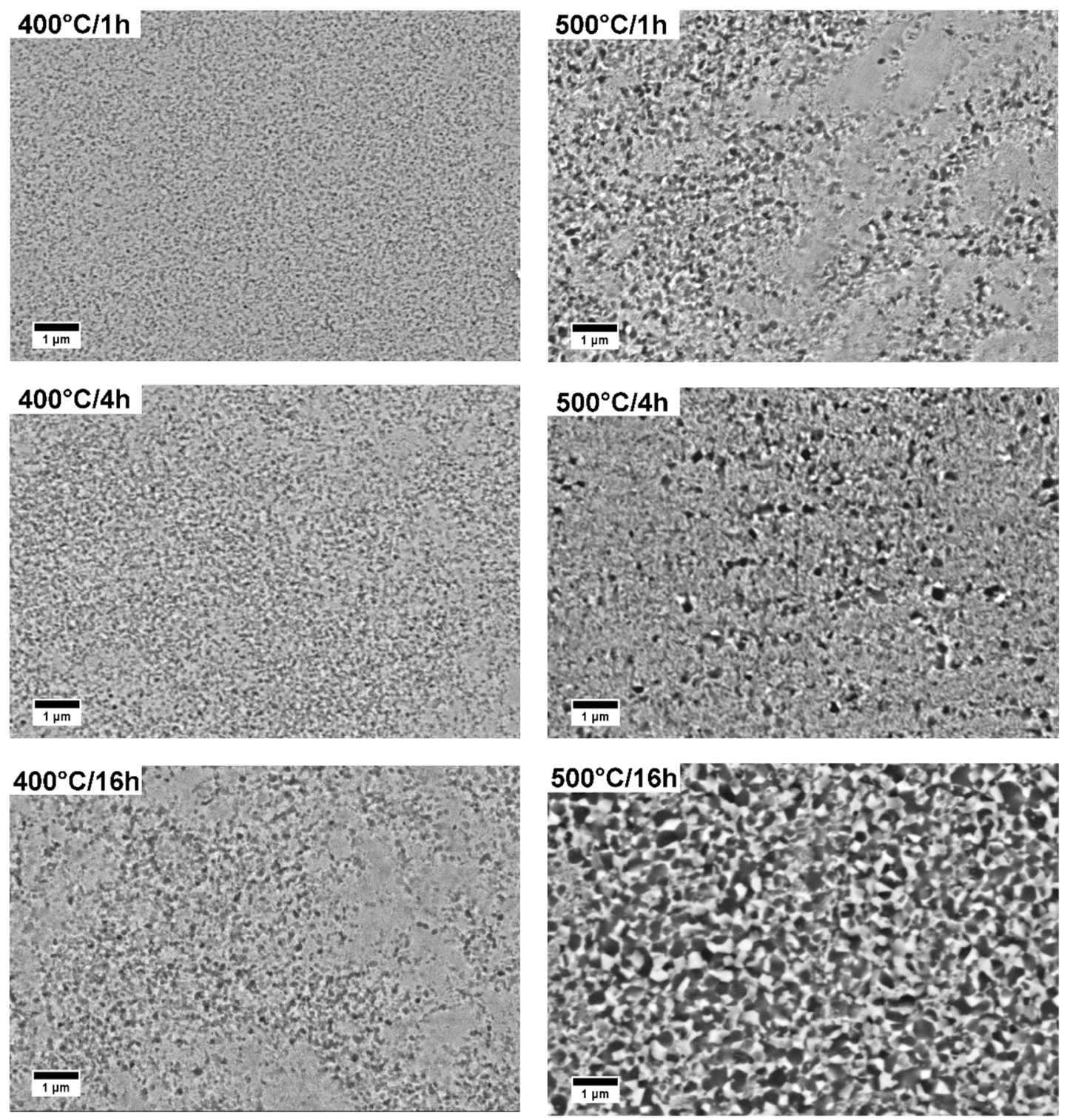

Figure 4. SEM-BSE images of the HPT samples after ageing at $400{ }^{\circ} \mathrm{C}$ and $500{ }^{\circ} \mathrm{C}$ for $1-16 \mathrm{~h}$ (ageing condition is indicated in the top left corner of each micrograph).

The evolution of defects in the HPT and RS samples after ageing were studied using PAS. The lifetime spectra of annihilated positrons are well described by two exponential components: the component with a shorter lifetime $\tau_{1}$ represents a contribution of free positrons, while the component with a longer lifetime $\tau_{2} \approx 170$ ps originates from positrons trapped at lattice defects, typically dislocations. The development of positron lifetimes after different ageing temperatures and times is shown in Figure 6a. The lifetime $\tau_{2}$ is approximately constant for all aged conditions, suggesting that the average size of openvolume defects remains unchanged during ageing. The lifetime $\tau_{1}$ for the RS sample does not change significantly with the ageing time for both ageing temperatures of $400{ }^{\circ} \mathrm{C}$ and $500{ }^{\circ} \mathrm{C}$. Nonetheless, the lifetime corresponding to positrons annihilated in the free state in the HPT specimens slightly increases with the ageing time for an ageing temperature of $400{ }^{\circ} \mathrm{C}$, suggesting a slight decrease in the concentration of lattice defects resulting in a higher fraction of positrons annihilated in the free state. 

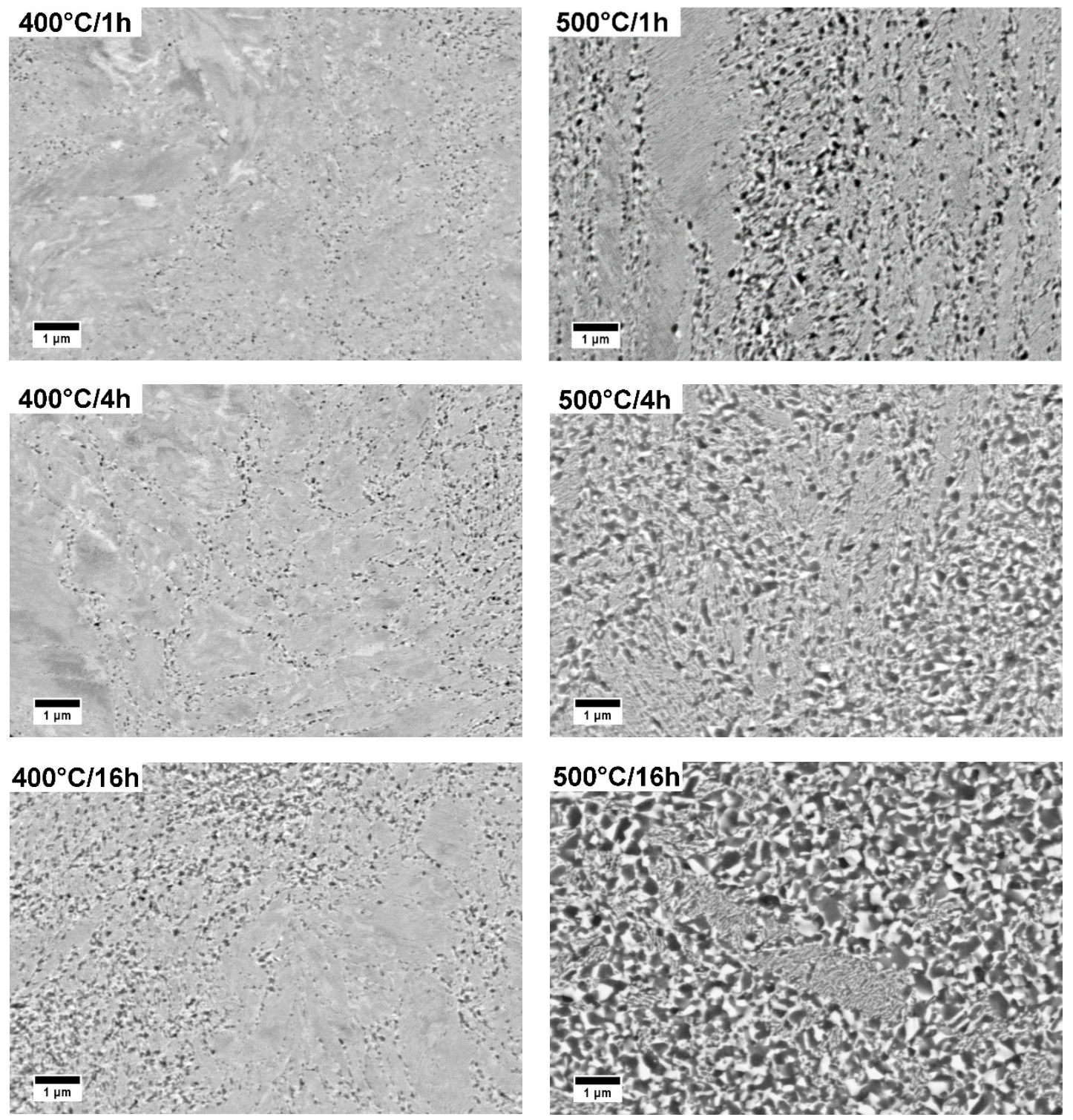

Figure 5. SEM-BSE images of the RS samples after ageing at $400{ }^{\circ} \mathrm{C}$ and $500{ }^{\circ} \mathrm{C}$ for $1-16 \mathrm{~h}$ (ageing condition is indicated in the top left corner of each micrograph).

Figure $6 \mathrm{~b}$ shows the dependence of the intensity $I_{2}$ of positrons trapped at lattice defects on the ageing time for both the HPT and the RS samples for ageing temperatures of $400{ }^{\circ} \mathrm{C}$ and $500{ }^{\circ} \mathrm{C}$. The component corresponding to positrons trapped at defects has a dominant intensity of around $98 \%$ for the HPT sample. This intensity gradually decreases with increasing ageing time at $400{ }^{\circ} \mathrm{C}$ due to the recovery of defects. However, the intensity $I_{2}$ for the ageing temperature of $500{ }^{\circ} \mathrm{C}$ remains constant within the experimental error, despite the fact that the recovery of defects introduced by deformation should also occur. This can be caused by an increasing fraction of incoherent $\alpha / \beta$ interfaces, which contain misfit defects also acting as traps for positrons [28]. During ageing of the material, precipitation of the $\alpha$ phase introduces new $\alpha / \beta$ interfaces and increases the concentration of these vacancy-like misfit defects. Since the lifetime of positrons trapped at misfit defects is comparable to the lifetime of positrons trapped at dislocations, distinguishing these components in the lifetime spectra is not possible and the component $\tau_{2}$ contains contributions both from positrons trapped at dislocations and misfit defects at $\alpha / \beta$ interfaces. 


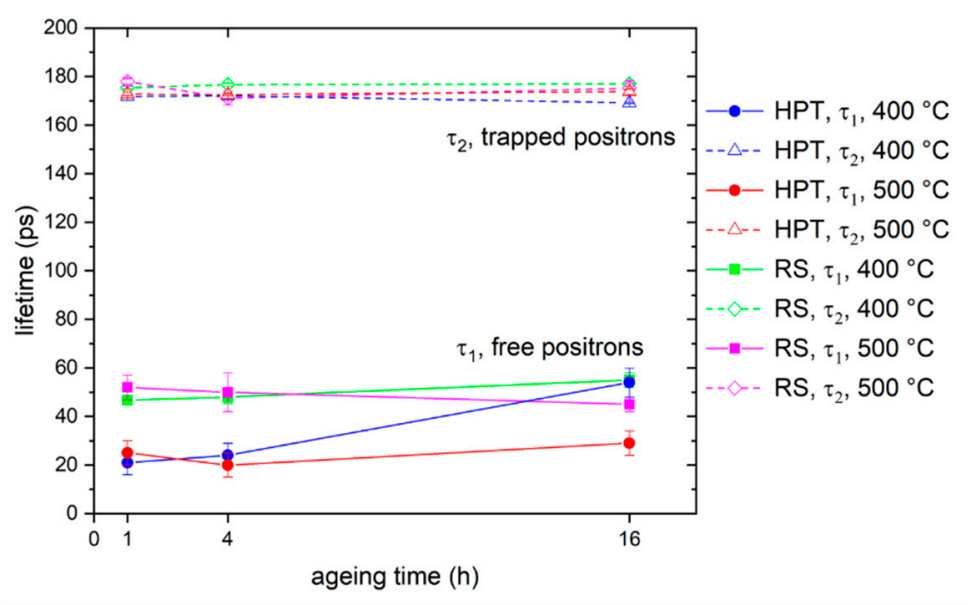

(a)

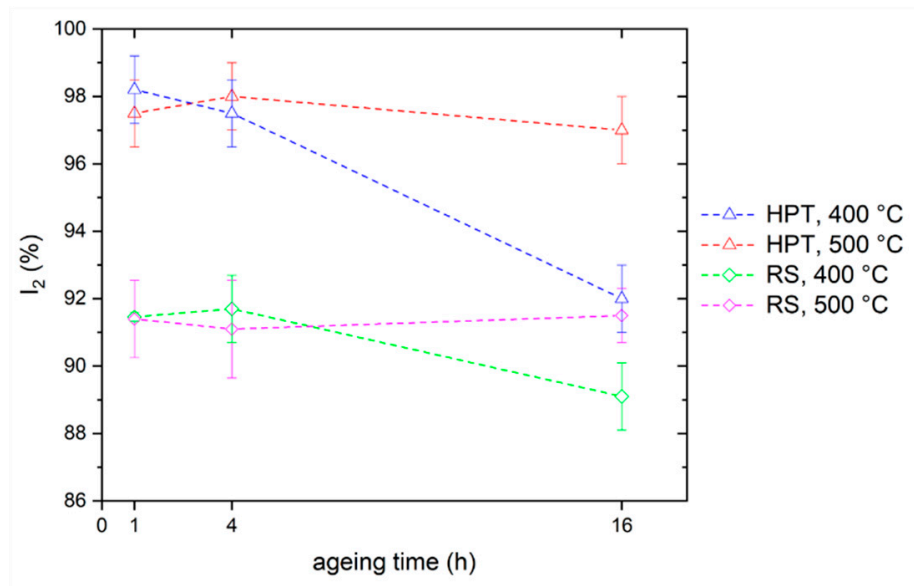

(b)

Figure 6. (a) Evolution of lifetime of positrons trapped at defects and of positrons annihilated in the free state with ageing time in the HPT and RS samples for ageing temperatures of $400{ }^{\circ} \mathrm{C}$ and $500{ }^{\circ} \mathrm{C}$. (b) Dependence of the intensity $I_{2}$ of positrons trapped at defects in the HPT and RS samples on ageing time for ageing temperatures of $400{ }^{\circ} \mathrm{C}$ and $500{ }^{\circ} \mathrm{C}$.

During aging of the RS specimens, the same trend as in the HPT ones was observed: the intensity $I_{2}$ decreases with increasing ageing time at $400{ }^{\circ} \mathrm{C}$, which can be ascribed to the recovery of lattice defects. On the other hand, the $I_{2}$ for the RS samples aged at $500{ }^{\circ} \mathrm{C}$ does not change significantly with increasing ageing time- the recovery of defects and creation of new positron traps in the form of $\alpha / \beta$ interfaces act against each other. However, it should be noted that the intensity $I_{2}$ of the RS specimen is lower $(\sim 91 \%)$ when compared to the HPT specimen ( $97 \%)$. This suggests a higher density of lattice defects in the HPT material.

\section{Discussion}

A Ti15Mo alloy was deformed by two different processes: high pressure torsion and cold-rotary swaging. The material after ST contains coarse $\beta$ grains with the size of $\sim 50 \mu \mathrm{m}$ as it was described in our previous studies $[15,16]$.

During HPT, the imposed deformation is 3600\% in the peripheral part of the sample with a $20 \mathrm{~mm}$ diameter, as calculated using the von Mises equation [22]. The imposed deformation by RS is more than one order of magnitude lower, calculated by the finite element model reported in [23] — the authors claim that equivalent strain cannot reach $200 \%$ even on the rim of the sample processed by RS. 
HPT straining results in the formation of a UFG structure of the Ti15Mo alloy [15,17,29-32]. In the rudimentary stage of the HPT deformation, a twinning process takes place, which is followed by significant grain refinement $[31,33,34]$. In contrast, deformation using RS creates shear bands with a high density of lattice defects and refined grains with an elongated character, as also reported in studies [35-38]. The shear bands are caused by the dislocation slip during $\mathrm{RS}$, while the elongated character of the grains is the result of the combination of a dislocation slip and a grain boundary slip [37].

The RS specimen aged at $400{ }^{\circ} \mathrm{C} / 1 \mathrm{~h}$ also contains small $\alpha$ particles. However, in comparison with the HPT sample, their volume fraction is lower. This is caused by the lower imposed strain in the RS specimen, which results in a lower density of precipitationenhancing lattice defects.

Nucleation and growth of the $\alpha$ phase continues during longer ageing at both ageing temperatures in both prepared conditions. The size of $\alpha$ phase particles does not exceed $1 \mu \mathrm{m}$. They remain equiaxed in all aged conditions. A high density of $\alpha$ nuclei is caused by a high density of preferential nucleation sites. However, the growth of $\alpha$ nuclei is limited by two processes. First, each $\alpha$ particle causes a barrier for the growth of another $\alpha$ particle due to mutual impingement. Second, each $\alpha$ particle creates a barrier for the diffusion of $\beta$-stabilizing Mo in the $\beta$ matrix. Therefore, the $\beta$ matrix stabilized by Mo around each $\alpha$ particle limits the diffusional growth of surrounding particles. Consequently, $\alpha$ phase particles remain small and equiaxed in zones with a high density of lattice defects.

Microstructure observations clearly indicate that the precipitation of the $\alpha$ phase is inhomogeneous in both materials. This phenomenon can be caused by local chemical inhomogeneities in the material or by inhomogeneities in the density of lattice defects.

Ti15Mo alloy in a solution treated condition contains local chemical inhomogeneities as was proved by energy dispersive spectroscopy [15]. These chemical inhomogeneities (darker and lighter bands observed using backscattered electrons in SEM) seem to be extended during HPT deformation in the direction of the deformation [15]. Therefore, the nucleation of the $\alpha$ phase particles may be promoted in the areas depleted in Mo. Some of the authors also observed lighter and darker bands in the HPT-deformed alloys $[19,20,39,40]$ which they ascribed to shear bands.

The formation of shear bands (areas with higher dislocation density) is typical in deformed alloys and can also cause an inhomogeneous precipitation of the $\alpha$ phase, as nucleation of the $\alpha$ phase is enhanced in areas with higher dislocation density [41]. This phenomenon has been described already in our previous studies [15-17] or in studies by other authors $[18,20]$. The growth of the $\alpha$ nuclei is diffusion-controlled and therefore is accelerated in the presence of a high density of dislocations as the pipe diffusion along dislocations is several orders of magnitude higher than the bulk diffusion [42].

Thus, the exact explanation of the origin of the lighter and darker bands in the deformed materials as well as the cause of the inhomogeneous precipitation of the $\alpha$ particles need further investigation.

Positron annihilation spectroscopy of severely deformed materials after ageing is usually utilized for monitoring the recovery of lattice defects during ageing $[43,44]$. The recovery of defects is manifested by an increasing intensity of the component related to the annihilation of free positrons (i.e., positrons not trapped in any lattice defect). A similar, though weak, trend is observed after ageing at $400^{\circ} \mathrm{C}$. On the other hand, ageing at $500{ }^{\circ} \mathrm{C}$ did not result in an increase of the free-positron component. This could be caused by the increasing fraction of incoherent $\alpha / \beta$ interfaces, which contain vacancy-like misfit defects which act as traps for positrons [28]. Since the lifetime of positrons trapped at misfit defects is comparable with that for dislocations, the distinction of these components in the lifetime spectra is not possible and the density of misfit defects and/or dislocations cannot be unambiguously determined. In conclusion, PAS measurement suggests that the recovery of lattice defects in the $\beta$ matrix already occurs at $400{ }^{\circ} \mathrm{C}$ and in terms of positron trapping is partly compensated by the precipitation of incoherent $\alpha$ phase particles. At $500{ }^{\circ} \mathrm{C}$, the 
precipitation is even more pronounced, and the recovery of positron trapping sites in the $\beta$ matrix is fully offset by the formation of incoherent $\alpha / \beta$ interfaces.

\section{Conclusions}

Ti15Mo, a metastable $\beta$-Ti alloy was deformed by two techniques, namely, high pressure torsion (HPT) and rotary swaging (RS). The following conclusions can be drawn from this experimental study:

- Isothermal ageing resulted in the precipitation of the $\alpha$ phase in both deformed conditions. The nucleation and growth of the $\alpha$ phase is enhanced by lattice defects. These particles remain small and equiaxed even after ageing at $500{ }^{\circ} \mathrm{C} / 16 \mathrm{~h}$.

- Positron annihilation spectroscopy revealed the kinetics of the recovery of lattice defects during ageing. The recovery of lattice defects in the $\beta$ matrix already occurs at $400^{\circ} \mathrm{C}$, while the precipitation of the $\alpha$ phase forms new misfit defects which act as traps for positrons.

- Both dislocations and grain boundaries have a great influence on the nucleation and growth of the $\alpha$ phase.

- The precipitation of the $\alpha$ phase follows a similar trend in both deformed materials.

Author Contributions: Conceptualization, K.B. and J.S.; methodology, K.B., A.V., V.P.; investigation: K.B., J.V., J.Č., resources, K.B., J.M. and M.J.; data curation, K.B. and A.V.; writing-original draft preparation, K.B. and J.S.; writing—review and editing, K.B., J.S. and J.Č.; supervision, K.B., J.S. and I.S., project administration, J.S. and M.J.; funding acquisition, J.S. and M.J. All authors have read and agreed to the published version of the manuscript.

Funding: This research was funded by the Czech Science Foundation under the project No. 2012624S. Partial financial support by the Ministry of Education, Youth and Sports, project no. LTAUSA 18045 and by ERDF under the project No. CZ.02.1.01/0.0/0.0/15 003/0000485 is also gratefully acknowledged. Computational resources were supplied by the project "e-Infrastruktura CZ" (eINFRA LM2018140) provided within the program Projects of Large Research, Development and Innovations Infrastructures.

Institutional Review Board Statement: Not applicable.

Informed Consent Statement: Not applicable.

Data Availability Statement: The data presented in this study are available on request from the corresponding author.

Conflicts of Interest: The authors declare no conflict of interest. The funders had no role in the design of the study; in the collection, analyses, or interpretation of data; in the writing of the manuscript, or in the decision to publish the results.

\section{References}

1. Lütjering, G.; Williams, J.C. Titanium; Engineering Materials, Processes; Springer: Berlin/Heidelberg, Germany, 2007; ISBN 978-3-540-71397-5.

2. Niinomi, M. Mechanical Biocompatibilities of Titanium Alloys for Biomedical Applications. J. Mech. Behav. Biomed. Mater. 2008, 1, 30-42. [CrossRef]

3. Li, H.F.; Zheng, Y.F. Recent Advances in Bulk Metallic Glasses for Biomedical Applications. Acta Biomater. 2016, 36, 1-20. [CrossRef] [PubMed]

4. Chen, Q.; Thouas, G.A. Metallic Implant Biomaterials. Mater. Sci. Eng. R Rep. 2015, 87, 1-57. [CrossRef]

5. Eisenbarth, E.; Velten, D.; Müller, M.; Thull, R.; Breme, J. Biocompatibility of $\beta$-Stabilizing Elements of Titanium Alloys. Biomaterials 2004, 25, 5705-5713. [CrossRef] [PubMed]

6. Zehetbauer, M.J.; Steiner, G.; Schafler, E.; Koznikov, A.V.; Korznikova, E.A. Deformation Induced Vacancies with Severe Plastic Deformation: Measurements and Modelling. Mater. Sci. Forum. 2006, 503, 57-64. [CrossRef]

7. Estrin, Y.; Vinogradov, A. Extreme Grain Refinement by Severe Plastic Deformation: A Wealth of Challenging Science. Acta Mater. 2013, 61, 782-817. [CrossRef]

8. Valiev, R.Z.; Islamgaliev, R.K.; Alexandrov, I.V. Bulk Nanostructured Materials from Severe Plastic Deformation. Prog. Mater. Sci. 2000, 45, 103-189. [CrossRef] 
9. Nag, S.; Banerjee, R.; Fraser, H.L. Intra-Granular Alpha Precipitation in Ti-Nb-Zr-Ta Biomedical Alloys. J. Mater. Sci. 2009, 44, 808-815. [CrossRef]

10. da Costa, F.H.; Salvador, C.A.F.; de Mello, M.G.; Caram, R. Alpha Phase Precipitation in Ti-30Nb-1Fe Alloys-Phase Transformations in Continuous Heating and Aging Heat Treatments. Mater. Sci. Eng. A 2016, 677, 222-229. [CrossRef]

11. Mantri, S.A.; Choudhuri, D.; Alam, T.; Viswanathan, G.B.; Sosa, J.M.; Fraser, H.L.; Banerjee, R. Tuning the Scale of $\alpha$ Precipitates in $\beta$-Titanium Alloys for Achieving High Strength. Scr. Mater. 2018, 154, 139-144. [CrossRef]

12. Jiang, B.; Emura, S.; Tsuchiya, K. Improvement of Ductility in Ti-5Al-5Mo-5V-3Cr Alloy by Network-like Precipitation of Blocky $\alpha$ Phase. Mater. Sci. Eng. A 2018, 722, 129-135. [CrossRef]

13. Duerig, T.W.; Terlinde, G.T.; Williams, J.C. Phase Transformations and Tensile Properties of Ti-10V-2Fe-3AI. MTA 1980, 11, 1987-1998. [CrossRef]

14. Furuhara, T.; Maki, T. Variant Selection in Heterogeneous Nucleation on Defects in Diffusional Phase Transformation and Precipitation. Mater. Sci. Eng. A 2001, 312, 145-154. [CrossRef]

15. Bartha, K.; Stráský, J.; Veverková, A.; Barriobero-Vila, P.; Lukáč, F.; Doležal, P.; Sedlák, P.; Polyakova, V.; Semenova, I.; Janeček, M. Effect of the High-Pressure Torsion (HPT) and Subsequent Isothermal Annealing on the Phase Transformation in Biomedical Ti15Mo Alloy. Metals 2019, 9, 1194. [CrossRef]

16. Bartha, K.; Veverková, A.; Stráský, J.; Veselý, J.; Minárik, P.; Corrêa, C.A.; Polyakova, V.; Semenova, I.; Janeček, M. Effect of the Severe Plastic Deformation by ECAP on Microstructure and Phase Transformations in Ti-15Mo Alloy. Mater. Today Commun. 2020, 22, 100811. [CrossRef]

17. Bartha, K.; Stráský, J.; Barriobero-Vila, P.; Šmilauerová, J.; Doležal, P.; Veselý, J.; Semenova, I.; Polyakova, V.; Janeček, M. In-Situ Investigation of Phase Transformations in Ultra-Fine Grained Ti15Mo Alloy. J. Alloys Compd. 2021, 867, 159027. [CrossRef]

18. Jiang, B.; Emura, S.; Tsuchiya, K. Formation of Equiaxed $\alpha$ Phase in Ti-5Al-5Mo-5V-3Cr Alloy Deformed by High-Pressure Torsion. J. Alloys Compd. 2018, 738, 283-291. [CrossRef]

19. Xu, W.; Edwards, D.P.; Wu, X.; Stoica, M.; Calin, M.; Kühn, U.; Eckert, J.; Xia, K. Promoting Nano/Ultrafine-Duplex Structure via Accelerated $\alpha$ Precipitation in a $\beta$-Type Titanium Alloy Severely Deformed by High-Pressure Torsion. Scr. Mater. 2013, 68, 67-70. [CrossRef]

20. Jiang, B.; Tsuchiya, K.; Emura, S.; Min, X. Effect of High-Pressure Torsion Process on Precipitation Behavior of $\alpha$ Phase in $\beta$-Type Ti-15Mo Alloy. Mater. Trans. 2014, 55, 877-884. [CrossRef]

21. Zhilyaev, A.P.; Langdon, T.G. Using High-Pressure Torsion for Metal Processing: Fundamentals and Applications. Prog. Mater. Sci. 2008, 53, 893-979. [CrossRef]

22. Valiev, R.Z.; Ivanisenko, Y.V.; Rauch, E.F.; Baudelet, B. Structure and Deformaton Behaviour of Armco Iron Subjected to Severe Plastic Deformation. Acta Mater. 1996, 44, 4705-4712. [CrossRef]

23. Moumi, E.; Ishkina, S.; Kuhfuss, B.; Hochrainer, T.; Struss, A.; Hunkel, M. 2D-Simulation of Material Flow During Infeed Rotary Swaging Using Finite Element Method. Procedia Eng. 2014, 81. [CrossRef]

24. Bečvář, F.; Čížek, J.; Procházka, I.; Janotová, J. The Asset of Ultra-Fast Digitizers for Positron-Lifetime Spectroscopy. Nucl. Instrum. Methods Phys. Res. Sect. A Accel. Spectrometers Detect. Assoc. Equip. 2005, 539, 372-385. [CrossRef]

25. Bečvář, F. Methodology of Positron Lifetime Spectroscopy: Present Status and Perspectives. Nucl. Instrum. Methods Phys. Res. Sect. B Beam Interact. Mater. At. 2007, 261, 871-874. [CrossRef]

26. Procházka, I.; Novotný, I.; Bečvář, F. Application of Maximum-Likelihood Method to Decomposition of Positron-Lifetime Spectra to Finite Number of Components. Mater. Sci. Forum 1997, 255-257, 772-774. [CrossRef]

27. Kilmametov, A.R.; Ivanisenko, Y.; Mazilkin, A.A.; Straumal, B.B.; Gornakova, A.S.; Fabrichnaya, O.B.; Kriegel, M.J.; Rafaja, D.; Hahn, H. The $\mathrm{A} \rightarrow \omega$ and $\mathrm{B} \rightarrow \omega$ Phase Transformations in Ti-Fe Alloys under High-Pressure Torsion. Acta Mater. 2018, 144, 337-351. [CrossRef]

28. Čížek, J. Characterization of Lattice Defects in Metallic Materials by Positron Annihilation Spectroscopy: A Review. J. Mater. Sci. Technol. 2018, 34, 577-598. [CrossRef]

29. Bartha, K.; Stráský, J.; Harcuba, P.; Semenova, I.; Polyakova, V.; Janeček, M. Heterogeneous Precipitation of the $\alpha$-Phase in Ti15Mo Alloy Subjected to High Pressure Torsion. Acta Phys. Pol. A 2018, 134, 790-793. [CrossRef]

30. Václavová, K.; Stráský, J.; Zháňal, P.; Veselý, J.; Polyakova, V.; Semenova, I.; Janeček, M. Ultra-Fine Grained Microstructure of Metastable Beta Ti-15Mo Alloy and Its Effects on the Phase Transformations. IOP Conf. Ser. Mater. Sci. Eng. 2017, $194,012021$. [CrossRef]

31. Václavová, K.; Stráský, J.; Polyakova, V.; Stráská, J.; Nejezchlebová, J.; Seiner, H.; Semenova, I.; Janeček, M. Microhardness and Microstructure Evolution of Ultra-Fine Grained Ti-15Mo and TIMETAL LCB Alloys Prepared by High Pressure Torsion. Mater. Sci. Eng. A 2017, 682, 220-228. [CrossRef]

32. Václavová, K.; Stráský, J.; Veselý, J.; Gatina, S.; Polyakova, V.; Semenova, I.; Janeček, M. Evolution of Microstructure and Microhardness in Ti-15Mo $\beta$-Ti Alloy Prepared by High Pressure Torsion. Available online: https:/ /www.scientific.net/MSF.879. 2555 (accessed on 30 May 2018).

33. Wang, X.L.; Li, L.; Mei, W.; Wang, W.L.; Sun, J. Dependence of Stress-Induced Omega Transition and Mechanical Twinning on Phase Stability in Metastable $\beta$ Ti-V Alloys. Mater. Charact. 2015, 107, 149-155. [CrossRef]

34. Zhou, X.; Min, X.A.; Emura, S.; Tsuchiya, K. Accommodative $\{332\}<113>$ Primary and Secondary Twinning in a Slightly Deformed $\beta$-Type Ti-Mo Titanium Alloy. Mater. Sci. Eng. A 2017, 684, 456-465. [CrossRef] 
35. Preisler, D.; Stráský, J.; Harcuba, P.; Halmešová, K.; Janeček, M. Cold Swaging and Recrystallization Annealing of Ti-Nb-Ta-Zr-O Alloy-Microstructure, Texture and Microhardness Evolution. MSF 2018, 941, 1132-1136. [CrossRef]

36. Cheng, J.; Wang, H.; Li, J.; Gai, J.; Ru, J.; Du, Z.; Fan, J.; Niu, J.; Song, H.; Yu, Z. The Effect of Cold Swaging Deformation on the Microstructures and Mechanical Properties of a Novel Metastable $\beta$ Type Ti-10Mo-6Zr-4Sn-3Nb Alloy for Biomedical Devices. Front. Mater. 2020, 7. [CrossRef]

37. Guo, W.Y.; Xing, H.; Sun, J.; Li, X.L.; Wu, J.S.; Chen, R. Evolution of Microstructure and Texture during Recrystallization of the Cold-Swaged Ti-Nb-Ta-Zr-O Alloy. Metall. Mater. Trans. A 2008, 39, 672-678. [CrossRef]

38. Guo, W.; Quadir, M.Z.; Ferry, M. The Mode of Deformation in a Cold-Swaged Multifunctional Ti-Nb-Ta-Zr-O Alloy. Met. Mat Trans. A 2013, 44, 2307-2318. [CrossRef]

39. Xu, W.; Wu, X.; Stoica, M.; Calin, M.; Kühn, U.; Eckert, J.; Xia, K. On the Formation of an Ultrafine-Duplex Structure Facilitated by Severe Shear Deformation in a Ti-20Mo $\beta$-Type Titanium Alloy. Acta Mater. 2012, 60, 5067-5078. [CrossRef]

40. Zafari, A.; Xia, K. Formation of Equiaxed $\alpha$ during Ageing in a Severely Deformed Metastable $\beta$ Ti Alloy. Scr. Mater. 2016, 124, 151-154. [CrossRef]

41. Porter, D.A.; Easterling, K.E.; Sherif, M.Y.A. Phase Transformations in Metals and Alloys, 3rd ed.; CRC Press: London, UK, 2009.

42. Legros, M.; Dehm, G. Obsevation of Giant Diffusivitiy along Dislocation Core. Science 2008, 319, 1646-1649. [CrossRef]

43. Bartha, K.; Zháňal, P.; Stráský, J.; Čížek, J.; Dopita, M.; Lukáč, F.; Harcuba, P.; Hájek, M.; Polyakova, V.; Semenova, I.; et al. Lattice Defects in Severely Deformed Biomedical Ti-6Al-7Nb Alloy and Thermal Stability of Its Ultra-Fine Grained Microstructure. J. Alloys Compd. 2019, 788, 881-890. [CrossRef]

44. Janeček, M.; Čížek, J.; Stráský, J.; Václavová, K.; Hruška, P.; Polyakova, V.; Gatina, S.; Semenova, I. Microstructure Evolution in Solution Treated Ti15Mo Alloy Processed by High Pressure Torsion. Mater. Charact. 2014, 98, 233-240. [CrossRef] 